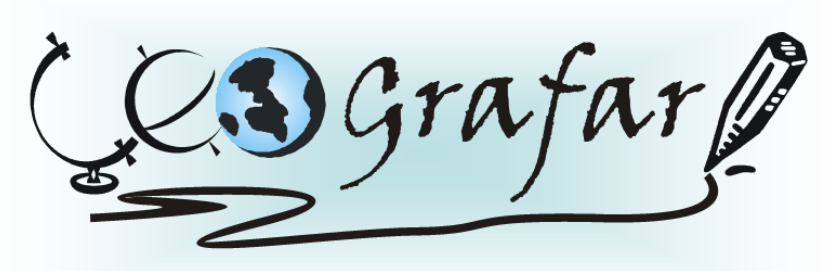

Revista Eletrônica do Programa de Pós-Graduação em Geografia - UFPR

\title{
ARBORIZAÇÃo VIÁRIA NA ÁREA CENTRAL DE PARANAGUÁ (PR) BRASIL
}

\author{
EMERSON LUIS TONETTI ${ }^{1}$ \\ JOÃO CARLOS NUCCI ${ }^{2}$
}

\begin{abstract}
RESUMO
A presença de árvores nas cidades traz inúmeros benefícios para a qualidade ambiental, portanto, devem ser consideradas no planejamento e na gestão da paisagem urbanizada. Na parte central da área urbana do município de Paranaguá (PR), foi realizada uma análise da qualidade e distribuição das árvores plantadas nas calçadas e canteiros centrais, como um novo critério do método para a determinação da Qualidade Ambiental Urbana. Os parâmetros indicaram como baixa qualidade ambiental ruas que apresentaram menos do que $50 \%$ de arborização; média nas ruas que apresentaram entre $50 \%$ e $75 \%$ de arborização e a rua com presença da arborização viária em mais de $75 \%$ do segmento foi caracterizada como de alta qualidade ambiental. Utilizando o programa AutoCAD, os dados coletados em campo foram lançados na carta base, na escala 1:15.000, para obtenção do mapa da qualidade da arborização viária. Constatou-se o predomínio de ruas com pouca ou nenhuma árvore, ou seja, com qualidade baixa no critério arborização viária, permitindo-se concluir que a arborização viária em Paranaguá não está contribuindo para a conectividade entre as manchas de cobertura vegetal e nem para a melhoria da qualidade ambiental.
\end{abstract}

Palavras-chave: Paranaguá; Arborização viária; Qualidade Ambiental Urbana; Planejamento da Paisagem; Paisagem Urbana

\footnotetext{
${ }^{1}$ IFPR- campus Paranaguá. emerson.tonetti@ifpr.edu.br

${ }^{2}$ DGEOG-UFPR. nucci@ufpr.br
} 


\title{
STREET ARBORIZATION IN THE CENTRAL AREA OF PARANAGUÁ, PARANÁ, BRAZIL
}

\begin{abstract}
Street arborization in cities are responsible for several benefits that can contribute to the environmental quality, and for this reason it should be considered for an effective urban landscape planning and management. It was analysed the quality and distribuition of the trees located on the sidewalks and bedflowers of the central area of Paranaguá (PR) as a new methodological criterion of determining the urban environmental quality. The parameters indicated low environmental quality for those streets where the arborization level was lower than 50\%. The streets with an afforestation/arborization level between $50 \%$ and $70 \%$ were classified as of average environmental quality, and a street afforestation/arborization of over $75 \%$ indicated a high environmental quality. The collected data were put on a base map, at a scale of 1:15.000 using the AutoCAD in order to create a map of the street arborization quality. Through the map it was observed the predominance of streets with low environmental quality. This has led to the conclusion that the street afforestation/arborization in Paranaguá is not contributing neither to the connectivity between the fragments of the vegetation cover nor to the environmental quality improvement.
\end{abstract}

Keywords: Paranaguá; Street arborization; Urban environmental quality; Landscape planning; Urban landscape

\section{INTRODUÇÃO}

A vegetação existente nas cidades traz muitos benefícios para a qualidade do ambiente urbano e, por essa razão, os estudos relacionados com a sua presença na paisagem urbana são fundamentais para o planejamento e a gestão desses ambientes.

A arborização viária, como parte da vegetação urbana, tem a potencialidade para elevar o índice e a conectividade da cobertura vegetal, melhorando a qualidade ambiental como um todo.

Foi realizada, na porção central da área urbana do município de Paranaguá (PR), uma avaliação da qualidade da distribuição da arborização viária, para verificar se existe a potencialidade para gerar benefícios ambientais e promover o aumento do índice de cobertura vegetal e a conectividade entre as manchas de vegetação. 
Paranaguá destaca-se no litoral paranaense pelo tamanho de sua população, 140.450 habitantes (IBGE, 2010), concentrados na área urbana do Município. Este valor corresponde, praticamente, à metade da população do litoral e a décima população do Estado. Possui importância regional e nacional pela presença do Porto Dom Pedro II ou Porto de Paranaguá, que atua como um dos principais agentes de transformação da paisagem local.

O critério arborização viária faz parte de um contexto de pesquisa que visa a determinação da Qualidade Ambiental Urbana e a identificação de áreas não adensáveis (TONETTI, 2011). Esse é um novo critério acrescentado ao método de determinação da Qualidade Ambiental Urbana desenvolvido por Nucci (1996, 2001, 2008), dentro da linha do Planejamento da Paisagem (NUCCl, 2009, 2010), uma teoria que incorpora a avaliação das potencialidades (limites e aptidões) da natureza e da paisagem para acolher os usos humanos.

\title{
2 REFERENCIAL TEÓRICO
}

Valaski (2008, p. 40) comenta que na dinâmica da urbanização é claramente perceptível a falta de importância que é atribuída à questão da presença de vegetação nas cidades. Valorizam-se os imóveis, o estilo arquitetônico, a localização, entre outros fatores, porém, não são feitas análises acerca da necessidade de se deixar no terreno espaços livres para o plantio de vegetação.

Nucci, $(2008$, p. 23) segue afirmando que:

\begin{abstract}
Dentro da linha metodológica do Planejamento da Paisagem, quando se fala em planejar com a natureza, está se falando principalmente da vegetação. É a partir dela que muitos problemas serão amenizados ou resolvidos e, portanto, a cobertura vegetal, tanto em termo qualitativo como quantitativo e também sua distribuição espacial no ambiente urbano, deve ser cuidadosamente considerada na avaliação da qualidade ambiental. (NUCCl, 2008, p. 23)
\end{abstract}

Sukopp e Werner (1991), Spirn (1995), Hough (1998), Palomo (2005), Fávero (2007) e Nucci (2008) chamam a atenção para a necessidade e importância do planejamento integrado da cobertura vegetal em diferentes escalas. Como destaca Nucci (2008) ao escrever que: 
(...) um jardim de um edifício também pode assegurar algumas condições de bem-estar público. Entretanto (...) O paisagismo doméstico por si só não é suficiente para resolver os problemas ecológicos das metrópoles. Para isso seriam necessários grandes parques, a arborização das margens dos rios e, também, das vias públicas. (NUCCl, 2008, p. 28)

Ainda, de acordo com Sukopp e Werner (1991) os jardins, a arborização das margens dos rios e das vias de tráfego podem criar uma superfície de integração entre áreas com maior índice de cobertura vegetal, ou seja, podem atuar como corredores ecológicos para espécies da flora e da fauna que possuem facilidade para dispersão a pequenas distâncias, mantendo-se, dessa forma uma, diversidade maior de espécies no conjunto pelo fluxo de organismos entre os fragmentos com maior e menor índice de cobertura vegetal, e do centro urbano com as áreas rurais circundantes.

Nucci e Cavalheiro (1999) e Nucci (2008, p. 23 e 24), com base em vários autores, citam os inúmeros benefícios que a vegetação pode trazer ao ser humano das cidades, tais como:

- estabilização de superfícies por meio da fixação do solo pelas raízes das plantas;

- proteção da qualidade da água, pois impede que substâncias poluentes escorram para os rios;

- proteção das nascentes e dos mananciais pela manutenção da área de captação e escoamento lento das águas pluviais por meio da trama de raízes e do acúmulo da serapilheira no solo que promovem a redução da velocidade da água e favorecem sua maior infiltração;

- redução da velocidade do vento e da poluição sonora por atuar como obstáculo (barreira mecânica) contra o vento e o excesso de ruído;

- filtração do ar, diminuindo a poeira em suspensão pelo aumento da superfície de adesão e absorção de gases poluentes representadas pela grande área foliar;

- equilíbrio do índice de umidade do ar e, por consequência da sua temperatura, por meio da absorção e retirada da água do solo e sua emissão na forma de vapor através do processo evaporação e da transpiração foliar;

- redução do efeito das ilhas térmicas por meio do sombreamento e da absorção dos raios solares, manutenção da umidade relativa do ar e favorecimento das correntes de ar que promovem sua renovação no local; 
- contato com a natureza e recreação, colaborando com a saúde física e psíquica do homem;

- produção de vegetais e frutas frescas na área urbana para o consumo humano;

- abrigo, fonte de alimento e local de reprodução da fauna;

- organização, caracterização, sinalização e composição de espaços no desenvolvimento das atividades humanas;

- anúncio das mudanças das estações pelas alterações fenológicas da vegetação ao longo do ano;

- quebra da monotonia das cidades, com cores relaxantes;

- estabelecimento de uma escala intermediária entre a humana e a construída.

Por causa dos benefícios e das funções que a vegetação é capaz de realizar na cidade, seria interessante que todas as possibilidades de aumento da cobertura vegetal nas áreas urbanizadas fossem incentivadas (SUKOPP e WERNER, 1991; NUCCI, 2008, p. 24). Desta forma, alternativas como a presença da vegetação nos telhados, nos muros e nas fachadas poderia aumentar o contato do ser humano com a natureza e prover as melhorias na qualidade do ambiente, mesmo nos centros densamente habitados e construídos.

Sukopp e Werner (1991) sugerem que os edifícios que tivessem, por exemplo, um jardim, ou uma trepadeira no muro, ou uma árvore na calçada, ou telhado verde poderiam ter seu imposto municipal reduzido. Neste sentido, estudos realizados na Alemanha demonstram um interesse nesse aspecto, quando são realizadas classificações dos tipos de áreas associando-se a elas um índice ("valor do biótopo") que é utilizado nos cálculos do desconto no imposto urbano, como demonstra Valaski (2008, p. 58). Esta autora destaca, também, que cada edificação é avaliada em relação a quanto ela contribui para fechar os ciclos dos materiais envolvidos e produzir um mínimo de impacto nos ecossistemas.

A arborização viária é parte integrante da cobertura vegetal do ambiente urbano. Destaca-se nesta paisagem porque se localiza entre as vias de tráfego de veículos, os pedestres e as edificações, desempenhando as inúmeras funções exemplificadas anteriormente e ainda, atuam como barreira física garantindo a segurança dos pedestres e ciclistas em seus deslocamentos diários. Além disso, elas podem potencializar os benefícios físicos facilitando a instalação de uma 
circulação renovadora do ar fresco e limpo vindo do entorno rural e na comunicação entre as manchas de cobertura vegetal do meio urbano e do entorno rural.

Contudo, de acordo com Hough (1998, p. 100) a arborização viária, também deve responder aos requisitos tecnológicos. Por exemplo, as raízes não podem interferir com os serviços subterrâneos, o espaço e altura dos ramos não devem competir com os cabos elétricos. Ainda, sua seleção envolve as convenções estéticas predominantes que, segundo Spirn (1995, p. 198), pode levar ao plantio em larga escala de uma única espécie. Isso pode levar à perda dessas árvores rapidamente por doenças ou fatores físicos.

Algumas medidas devem ser consideradas para melhorar as condições do ambiente local para aumentar a longevidade e, consequentemente, a viabilidade econômica da manutenção e implantação da arborização viária. Visto que estes locais não são autoregeneradores, à medida que as árvores declinam, a paisagem precisa ser perpetuada pelo plantio de novas árvores. Estas plantas precisam de cuidados constantes, por isso os custos são elevados e de acordo com Hough (1998,p. 115) e Spirn (1995, p. 223), o fator econômico é decisivo para a existência das árvores das ruas.

A ausência ou insuficiência de um único fator limitante, seja a água, o ar, a luz ou os nutrientes vai resultar primeiramente em uma redução de seu crescimento e, depois em seu declínio e morte. Quando isto acontece, pesquisadores devem visitar o local e procurar descobrir as causas, sugerir e revisar as técnicas de plantio, antes que as árvores sejam substituídas (SPIRN, 1995, p. 203 e 204).

A maior parte da flora presente nas cidades pertence a umas poucas espécies que são as preferidas, por motivos econômicos entre outros. A adoção desse tipo de medida simplificadora pode criar problemas como a mortalidade em massa por motivos de doença (SUKOPP e WERNER, 1991 p. 46).

O sucesso será mais garantido se as árvores forem selecionadas dentre as espécies apropriadas, plantadas de forma adequada e mantidas com cuidado. Esta é uma combinação necessária para as árvores serem mantidas nos ambientes urbanos (SPIRN, 1995, p. 208; SUKOPP e WERNER, 1991, p. 46).

Um inventário arbóreo quantitativo e qualitativo pode ajudar a descobrir os locais que possuem déficit de arborização viária e ou os locais que apresentam árvores que precisam ser tratadas ou trocadas. Esse inventário também pode 
mostrar a distribuição das espécies e indicar os locais mais adequados para cada espécie.

\section{MÉTODO}

\section{1 ÁREA DE ESTUDO}

O recorte espacial da pesquisa engloba a parte central da área urbana do Município de Paranaguá, no litoral do Estado do Paraná. A área total do município é de $826,65 \mathrm{~km}^{2}$, sua área urbana é de $95,15 \mathrm{~km}^{2}$ e o local de estudo possui $11,64 \mathrm{~km}^{2}$ (FIGURA 1).

O marco zero do município encontra-se nas coordenadas $25^{\circ} 18^{\prime} 00^{\prime \prime} \mathrm{S}$ e $48^{\circ}$ 21' 00" W. Limita-se ao norte com a Baía de Paranaguá e o município de Guaraqueçaba (PR), ao sul com os municípios de Guaratuba (PR) e Matinhos (PR), a leste com o município de Pontal do Paraná (PR) e a oeste com os municípios de Antonina (PR) e Morretes (PR).

A cobertura vegetal original da área urbanizada de Paranaguá era constituída pela Floresta Ombrófila Densa das Terras Baixas em associações com a Floresta Ombrófila Densa Aluvial, com as formações pioneiras com influência marinha (restingas), com influência fluviomarinhas (manguezais e campos salinos) e com influência fluvial (taboais, caxetais, maricazais) de acordo com o sistema de classificação da vegetação brasileira, proposto pelo IBGE (1992). Atualmente são encontrados poucos remanescentes das formações florestais em diferentes estágios da sucessão vegetal e algumas áreas com formações pioneiras com influência fluviomarinha. 
Figura 1 - Localização da área de estudo com alguns pontos de referência

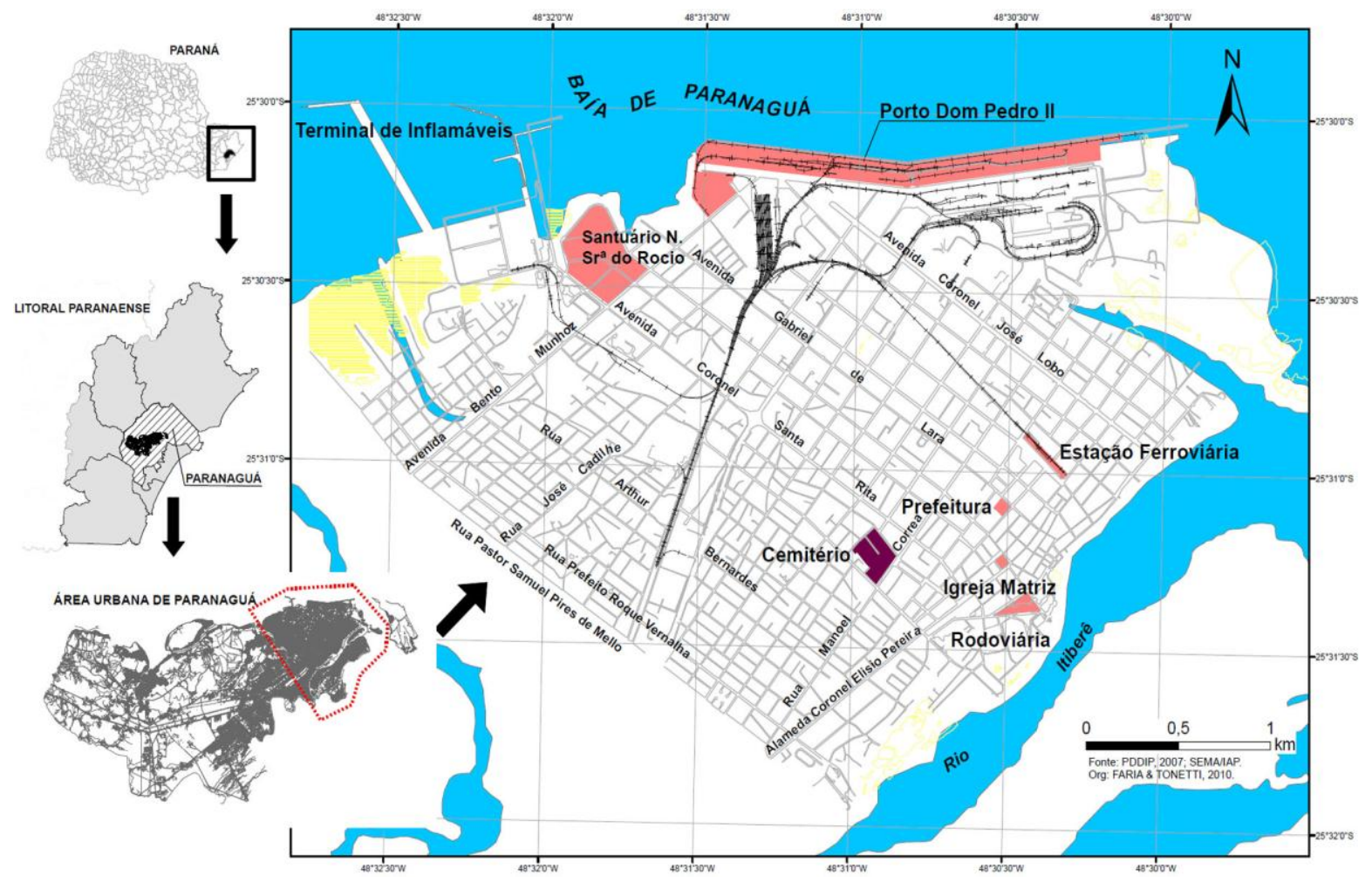

Organização: O autor.

\subsection{PROCEDIMENTOS}

Fez-se no local, por meio de trabalho de campo, o levantamento da qualificação da arborização viária, ou seja, do conjunto das árvores que crescem sobre a calçada e canteiros centrais de avenidas, próximas às vias de tráfego de veículos, em cada segmento de rua.

Foram mapeadas todas as árvores, acima de $2 \mathrm{~m}$ de altura e com copa visualmente superior a $1,5 \mathrm{~m}$ de diâmetro.

Optou-se em utilizar como unidade de representação a rua e a quadra, avaliando desta forma o conjunto, ou seja, as calçadas de ambos os lados de cada rua, de cada um dos lados de uma quadra. Esta unidade de representação foi denominada de segmento de rua.

Os segmentos das ruas que não apresentavam árvores regularmente distribuídas em ambos os lados das calçadas foram consideradas com baixa potencialidade para fornecer os benefícios oriundos da arborização viária. 
Considerou-se que a ausência da arborização viária em mais de $50 \%$ do segmento da rua caracterizava baixa potencialidade; os segmentos de rua que apresentavam entre $50 \%$ e $75 \%$ de árvores regularmente distribuídas pela calçada foram considerados como média potencialidade dos benefícios e a presença da arborização viária em mais de $75 \%$ do segmento de rua caracterizava alta potencialidade (Figura 2). 
Figura 2 - Critérios e parâmetros de avaliação da potencialidade dos benefícios da arborização viária.

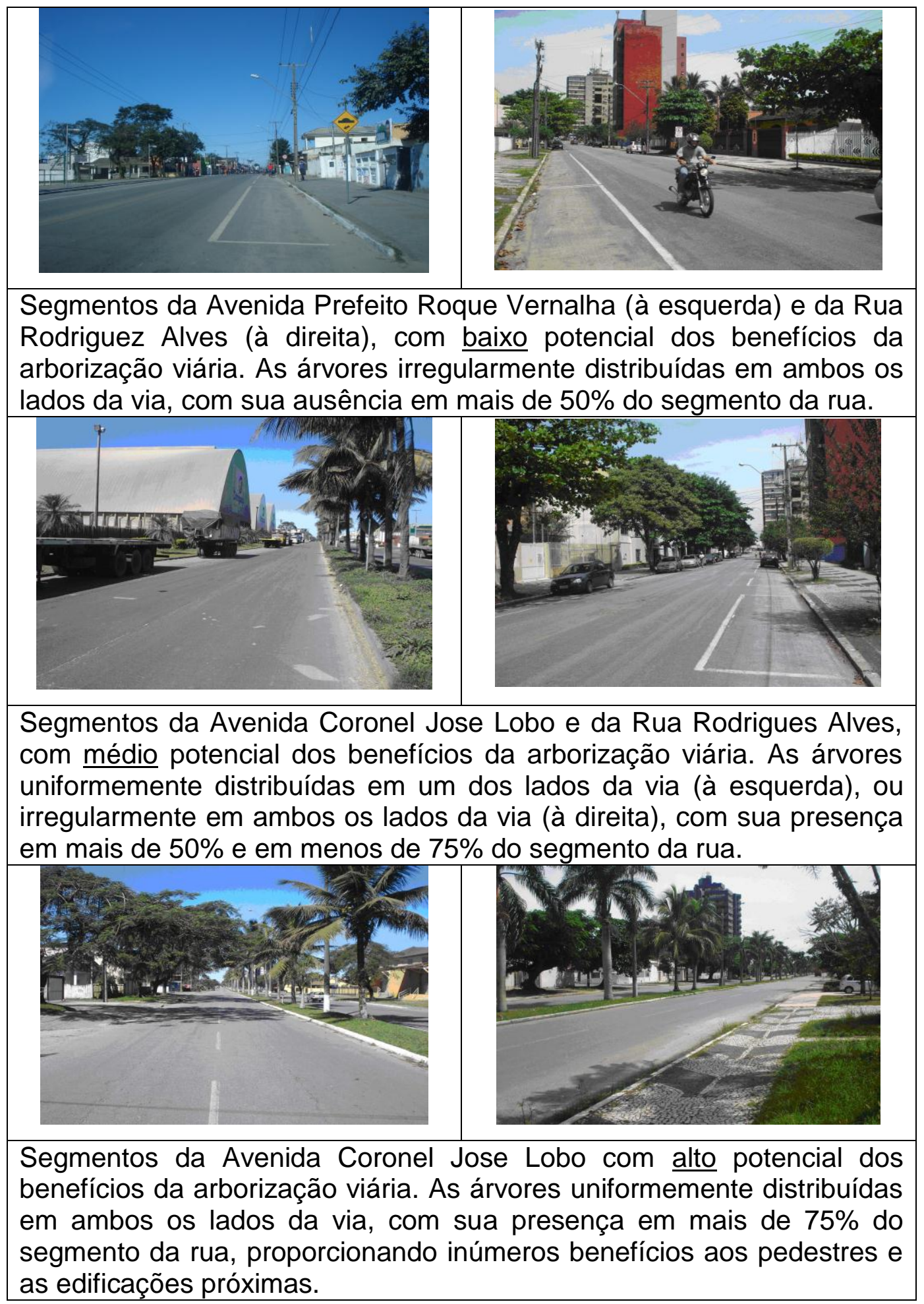

Organização: O autor. 


\section{RESULTADOS E DISCUSSÕES}

Na arborização viária de Paranaguá foi constatada a predominância de ruas com pouca ou nenhuma árvore, com exceção de alguns trechos na Avenida Coronel José Lobo e Gabriel de Lara.

Com base na espacialização da potencialidade da arborização em proporcionar benefícios (Figura 3), notou-se um pequeno predomínio do número de árvores na porção leste. Ao sul, observaram-se vários trechos de ruas com potencial médio, no entanto, não há continuidade desses segmentos, o que reduz os potenciais benefícios ambientais.

Apesar de a arborização viária fazer parte da cobertura vegetal, sua contribuição para a composição da mesma, na área urbana de Paranaguá, é pequena devido a predominância de ruas sem ou com número reduzido de árvores.

Além disso, as árvores são de porte pequeno, com baixo desenvolvimento de copa, estando associadas a um grande número de palmeiras, cujas copas também não são volumosas, não são identificadas, por exemplo, em levantamentos que utilizam escalas da ordem de 1:15.000, como as utilizadas por Tonetti (2011) na avaliação da qualidade ambiental urbana do município de Paranaguá.

Essa constatação torna a situação da cobertura vegetal ainda mais preocupante, porque a maioria das ruas não apresenta arborização viária ou ela é reduzida e, naquelas em que as condições foram classificadas como média ou alta, muitas das copas das árvores são pequenas por características inerentes da espécie. Dessa maneira, são ainda menores as perspectivas de ampliação da conectividade e do aumento da cobertura vegetal na área urbana de Paranaguá.

Também foram encontradas árvores senescentes e mortas nas avenidas com intenso tráfego de caminhões que, possivelmente, não suportaram as condições físicas e químicas locais, tais como: a compactação e a falta de água ou de nutrientes no solo, o excesso de poeira sobre suas folhas e o estresse causado pelo vento e pela fumaça proveniente dos automóveis e caminhões nas vias rodoviárias e ferroviárias. 
Figura 3 - Carta de distribuição e qualificação da arborização viária na porção central da área urbana do município de Paranaguá (PR).

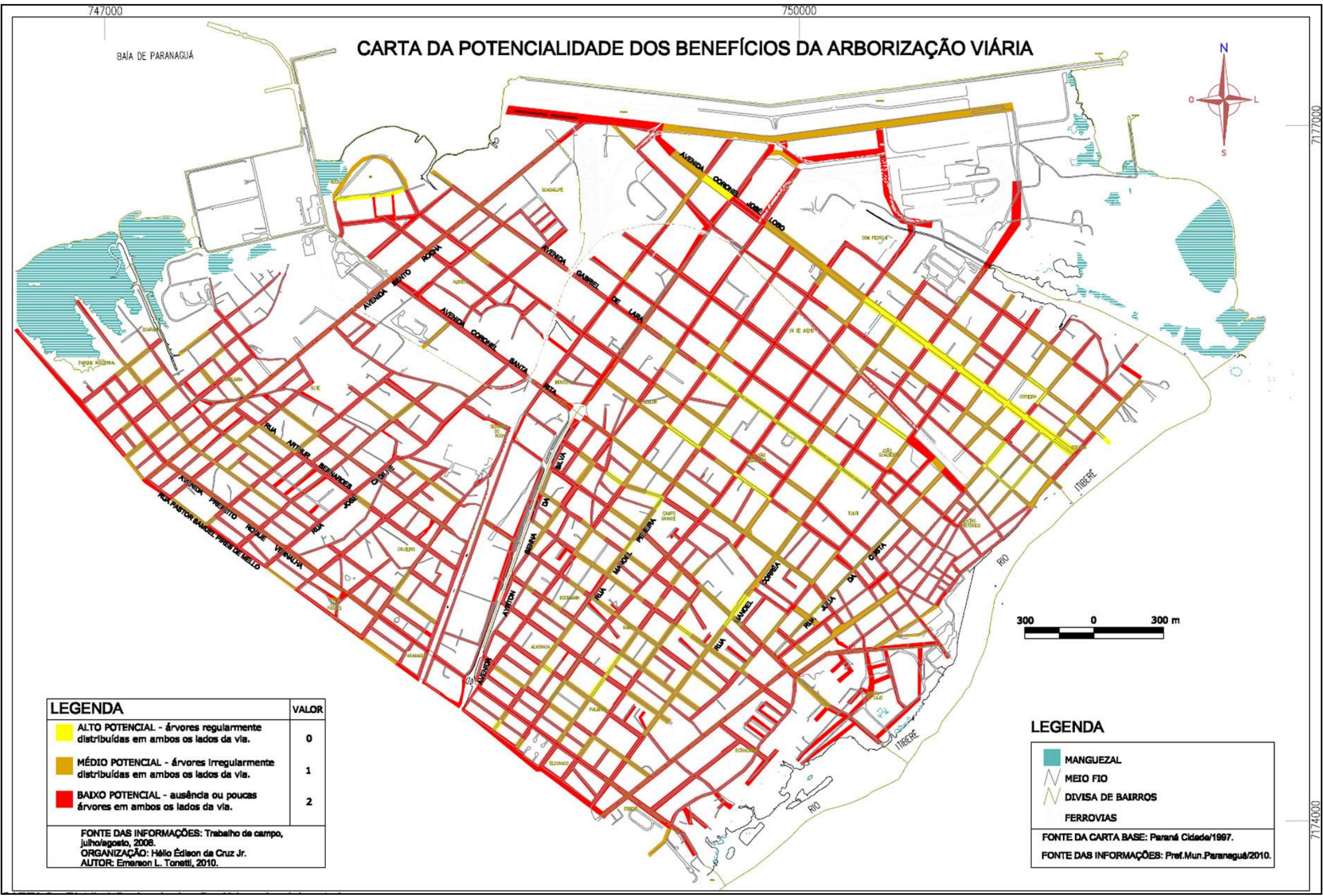


Outra constatação do trabalho de campo foi a ocorrência de calçadas quebradas e com desníveis decorrentes do aumento de volume das raízes das árvores. Outros problemas existem, porém eles podem ser evitados com a escolha da espécie e do manejo adequado dos indivíduos que compõem a arborização viária.

Medidas deveriam ser tomadas pelo poder público no sentido de revitalizar a arborização viária em Paranaguá, pensando-se em uma arborização que proporcione melhorias na qualidade do ambiente urbano pelo aumento da cobertura vegetal total e pelo aumento da conectividade entre as manchas de vegetação, garantindo os benefícios físicos e estéticos que a arborização pode proporcionar.

\section{CONCLUSÃO}

A arborização viária faz parte da cobertura vegetal de uma cidade e está em destaque na paisagem urbana porque se localiza entre as vias de tráfego de veículos, os pedestres e as edificações, desempenhando inúmeras funções que melhoram a qualidade do ambiente urbano, mas, apesar de sua importância, em Paranaguá predominam ruas com pouca ou nenhuma árvore, ou seja, a qualidade da arborização viária é baixa.

Conclui-se, portanto, que a atual distribuição da qualidade da arborização viária em Paranaguá não contribui significativamente com os benefícios ambientais, com a área total da cobertura vegetal, com a realização da conectividade entre as manchas de vegetação do meio urbano e destas com 0 entorno rural, não garantindo também a distribuição homogênea da qualidade ambiental.

Com base no que foi observado, pode-se inferir que a arborização viária em Paranaguá não foi planejada para a obtenção nem para a manutenção dos benefícios ecológicos e estéticos que ela pode prover.

Mesmo nos centros densamente habitados e construídos, alternativas como os cuidados com a arborização viária a ampliação da área com vegetação nas praças e em outros locais públicos e, a inserção de vegetação nos telhados, muros e fachadas poderiam aumentar o contato do ser humano com a natureza e prover as melhorias na qualidade do ambiente. 


\section{REFERÊNCIAS}

FÁVERO, O. A. Paisagem e sustentabilidade na bacia hidrográfica do rio Sorocaba (SP). 330 p. Tese (Doutorado em Geografia Humana) - Faculdade de Filosofia, Letras e Ciências Humanas da Universidade de São Paulo, São Paulo, 2007. Disponível em www.geografia.ufpr.br/laboratorios/labs/?pg=publicacoes-php Acesso em 15 dezembro 2008.

HOUGH, M. Naturaleza y ciudad: planificacion urbana y processos ecologicos. Barcelona: G. Gilli, 1998. 315 p.

IBGE - Fundação Instituto Brasileiro de Geografia e Estatística. Manual Técnico da Vegetação Brasileira. Série manuais técnicos em Geociências. 1992.

IBGE. Instituto Brasileiro de Geografia e Estatística. Cidades, Paranaguá, 2010. Disponvel em: http://www.ibge.gov.br/cidadesat/painel/painel.php?codmun=411820. Acesso em: 12 fevereiro 2011.

$\mathrm{NUCCl}$, J. C. Qualidade ambiental e adensamento: um estudo de Planejamento da Paisagem do distrito de Santa Cecília (MSP). Tese de doutorado. Universidade de São Paulo. Programa de Pós-Graduação em Geografia Física. 1996.

$\mathrm{NUCCI}$, J. C. Qualidade Ambiental e Adensamento Urbano: um estudo de ecologia e planejamento da paisagem aplicado ao distrito de Santa Cecília (MSP). São Paulo: Ed. Humanitas/FFLCH/USP, 2001 (1를. ed.). 236 p.

$\mathrm{NUCCl}$, J. C. Qualidade Ambiental e Adensamento Urbano: um estudo de ecologia e planejamento da paisagem aplicado ao distrito de Santa Cecília (MSP). Curitiba: Edição do autor (ISBN 978-85-908251-0-4), 2008 (2ª ed.). 142p. Disponível em www.geografia.ufpr.br/laboratorios/labs/?pg=publicacoes-php Acesso em 15 dezembro 2008.

NUCCl, J. C. Ecologia e Planejamento da Paisagem. In: Douglas Gomes dos Santos; João Carlos Nucci. (Org.). Paisagens Geográficas. Um tributo a Felisberto Cavalheiro. Campo Mourão: Editora da FECILCAM, 2009, p. 50-64. Disponível em http://www.fecilcam.br/editora/index.php?option=com content\&task=blogcategory \&id=6\&ltemid=12 Acesso em 28 abril 2010.

$\mathrm{NUCCl}$, J. C. Aspectos teóricos do Planejamento da Paisagem. In: Planejamento da Paisagem como subsídio para a participação popular no desenvolvimento urbano. Estudo aplicado ao bairro de Santa Felicidade Curitiba/PR. / Organização de João Carlos Nucci. Curitiba: LABS/DGEOG/UFPR, 2010, p. 14-25. $\quad$ Disponível em www.geografia.ufpr.br/laboratorios/labs/?pg=publicacoes-php Acesso em 20 agosto 2008. 
NUCCI, J. C.; CAVALHEIRO, F. Cobertura vegetal em áreas urbanas - conceito e método. Geousp, São Paulo, v. 6, n. 6, p. 29-36, 1999.

PALOMO, P. J. S. La planificación verde em las ciudades. 1 ed. Barcelona: Gustavo Gili, 2005. 326p.

SPIRN, A. W. O Jardim de Granito: A Natureza no Desenho da Cidade. São Paulo, Editora da Universidade de São Paulo, 1995.

SUKOPP, H.; WERNER, P. Naturaleza em las ciudades. Madrid: Ministério de Obras Públicas y Transportes (MOPT), 1991.

TONETTI, E. L. Potencialidades de adensamento populacional por verticalização das edificações e qualidade ambiental urbana no município de Paranaguá, Paraná, Brasil. 235f. Tese (Doutorado) - Setor de Ciências da Terra, Universidade Federal do Paraná, Curitiba. 2011. Disponível em http://200.17.203.155/index.php?codigo sophia=285569 Acesso em 12 abril 2011.

VALASKI, S. Avaliação da qualidade ambiental em condomínios residências horizontais com base nos princípios do planejamento da paisagem. Estudo de caso: bairro Santa Felicidade - Curitiba/PR. 138 f. Dissertação (Mestrado) Setor de Ciências da Terra, Universidade Federal do Paraná, Curitiba. 2008. Disponível em www.geografia.ufpr.br/laboratorios/labs/?pg=publicacoes-php. Acesso em 15 janeiro 2009.

(Recebido em 15.08.2011. Aceito em 13.02.2012) 